\title{
Analisis Penerapan Sistem Proteksi Kebakaran Aktif Dalam Upaya Pencegahan dan Penanggulangan Bahaya Kebakaran Di PTPN IV Unit PKS Pabatu, Serdang Bedagai
}

\section{The Application Analysis Of Active Protection Systems In Efforts To Prevent And Overcome Fire Danger At PTPN IV Pabatu Business Unit, Serdang Bedagai}

\author{
Ester Saripati Harianja*1, Mestika Lumban Toruan², Anita Syahfitri Hasibuan ${ }^{3}$ \\ ${ }^{1,3}$ Program Studi Ilmu Kesehatan Masyarakat (S1) \\ ${ }^{2}$ Program Studi D3 Kebidanan \\ Fakultas Farmasi dan Ilmu Kesehatan Universitas Sari Mutiara Indonesia \\ *Korespondensi Penulis : esterharianja25@gmail.com, tikatoruan@yahoo.com, \\ anitasyahfitrihsb832@gmail.com
}

\begin{abstract}
ABSTRAK
PTPN IV Unit PKS Pabatu merupakan Pabrik minyak nabati yang gedungnya termasuk dalam kategori mudah terbakar. Kegiatan produksinya juga memiliki potensi kebakaran akibat penggunaan peralatan yang dapat menghasilkan suhu yang tinggi. Perlu adanya analisis penerapan sistem proteksi kebakaran aktif sebagai upaya pencegahan dan penanggulangan terhadap bahaya kebakaran. Tujuan umum dari penelitian ini adalah untuk mengetahui penerapan sistem proteksi kebakaran aktif dalam upaya pencegahan dan penanggulangan bahaya kebakaran di PTPN IV Unit PKS Pabatu. Metode penelitian yang digunakan adalah penelitian kualitatif dengan jenis studi kasus. Hasil penelitian yang didapatkan bahwa tingkat pemenuhan sistem proteksi aktif di area PTPN IV Unit PKS Pabatu sebesar 41,34\% sesuai dengan peraturan perundangan yaitu alarm kebakaran 37,5\% sesuai dengan Permenaker No.Per.02/MEN/1983, hidran 69,2\% sesuai dengan Keputusan Menteri PU No.10/KPTS/2000, APAR 100\% sesuai dengan Permenaker No.Per 04/Men/1980, tidak terdapat detektor dan sprinkler. Saran untuk pihak PTPN IV yaitu melakukan peninjauan ulang dan penambahan alarm kebakaran serta melengkapi sistem proteksi aktif seperti pengadaan sistem detektor dan sprinkler yang belum terdapat pada area pabrik PTPN IV Unit PKS Pabatu.
\end{abstract}

\section{Kata kunci : Kebakaran, Sistem Proteksi Aktif, Preventif}

\section{ABSTRACT}

PTPN IV Pabatu Business Unit is a vegetable oil factory in which the building is categorized flammable. Besides, its manufacturing process also has potential to cause fire as the results of the overheat machines. Therefore, it is necessary to analyze the implementation of Active Fire Protection System as a strategy of fire hazard prevention and management. The objective of the study was to identify the implementation of active fire protection system as a strategy to prevent and manage fire hazard at PTPN IV Pabatu Business Unit. The study employed qualitative method with case study design. This study obtained that the percentage of compliance of active protection system in the area of PTPN IV Pabatu Business Unit was $41.34 \%$ following the minimum level of fire alarm $37.5 \%$ as it is mentioned in Regulation of Minister of Manpower (Permenaker) No. Per.02/MEN/1983, the percentage of hydrant was $69.2 \%$ in accordance with the Public Works Ministerial Decree No.10/KPTS/2000, the use of light fire extinguisher was $100 \%$, in accordance with the Regulation of Minister of Manpower (Permenaker) No.Per 04/Men/1980. However, the use of detector and sprinkler was not found in this study. It is suggested that the management of PTPN IV should carry out regular monitoring and add fire alarm as well as complete the active protection system equipment such as detector and sprinkle in the area of PTPN IV Pabatu Business Unit.

Keywords: Fire, Active Protection System 


\section{PENDAHULUAN}

Kebakaran di industri merupakan salah satu hal yang tidak hanya dapat menghilangkan harta benda maupun nyawa, tetapi juga mengganggu keberlangsungan kegiatan operasional sehingga mengganggu stabilitas dan kontinuitas kegiatan industri yang pada akhirnya menyebabkan semakin besarnya kerugian finansial yang ditanggung oleh perusahaan (Kowara and Martiana, 2017).

Berdasarkan data International Labour Organization (ILO) tahun 2012 kasus kebakaran pada sektor industri di dunia mengakibatkan 426 orang meninggal. Dari total korban meninggal tersebut, 67,8\% korban berasal dari pabrik garmen, 14,6\% korban berasal dari pabrik kilang minyak, 8,7\% korban berasal dari pabrik kembang api, 5,9\% korban berasal dari pabrik sepatu, 2,8\% korban berasal dari pabrik karet buatan, 0,2\% korban berasal dari pabrik petasan (Azmi and S.L, 2018).

Kebakaran dapat disebabkan oleh berbagai macam faktor, namun secara umum faktor-faktor yang menyebabkan kebakaran yaitu faktor manusia dan faktor teknis. Kasus kebakaran di Indonesia sekitar 62,8\% disebabkan oleh listrik atau adanya hubungan pendek arus listrik. Penataan ruang dan minimnya prasarana penanggulangan bencana kebakaran juga berkontribusi terhadap timbulnya kebakaran, khususnya kebakaran kawasan industri dan pemukiman.

Kerugian yang timbul akibat kebakaran antara lain kerugian jiwa, kerugian materi, menurunnya produktivitas, gangguan bisnis, dan kerugian sosial. Pada tahun 2010, dari 1.331 .500 kejadian kebakaran di Amerika Serikat, jumlah kerugian yang ditimbulkan antara lain kematian sebanyak 3.120 jiwa, 17.720 injuri, dan kerugian langsung karena rusaknya properti sebesar 11.593.000.000 dolar. Sedangkan di DKI Jakarta pada tahun 2016 mengalami 1.139 kasus kebakaran. Kasus terbanyak diakibatkan oleh korsleting listrik yakni 836 kasus. Peristiwa kebakaran itu telah menelan korban tewas 20 orang dan kerugian bagi 3. $618 \mathrm{KK}$ atau 11.719 jiwa, kerugian material mencapai Rp. 212.000.000.000, dengan objek terbanyak yang terbakar adalah bangunan perumahan mencapai 343 unit (Priambudi, Kurnawan and Widjasena, 2017).

Kebun Pabatu adalah salah satu unit usaha dari PT. Perkebunan Nusantara IV (Persero) yang berada di Desa Kedai Damar, Kecamatan Tebing Tinggi, Kabupaten Serdang Bedagai dan berkantor pusat di Jalan Letjend Suprapto Medan. Kebun Pabatu memiliki dua buah pabrik pengolahan yang terdiri dari : 1) Pabrik Kelapa Sawit (PKS) dan 2) Pabrik Pengolahan Inti Sawit ( PPIS). Berdasarkan Keputusan Menteri Tenaga Kerja No. 186/MEN/1999 tentang Unit Penanggulangan Kebakaran Di Tempat Kerja, Kebun Pabatu sebagai industri minyak nabati termasuk dalam kategori industri dengan potensi bahaya kebakaran sedang 3, yaitu tempat kerja yang mempunyai jumlah dan kemudahan terbakar tinggi, dan apabila terjadi kebakaran melepaskan panas tinggi, sehingga menjalarnya api cepat (Kemnaker RI, 1999). Kawasan industri khususnya yang menggunakan bahan yang mudah terbakar dan terdapat proses kerja sangat berpotensi menimbulkan kebakaran memiliki tingkat risiko kebakaran yang lebih tinggi dibandingkan dengan perkotaan, pemukiman dan tempat umum. Untuk itu Undangundang Nomor 1 tahun 1970 tentang keselamatan kerja telah mengatur bahwa setiap tempat kerja harus melakukan upaya untuk menciptakan tempat kerja yang sehat dan selamat, termasuk dari bahaya kebakaran (Priambudi, Kurnawan and Widjasena, 2017).

Keputusan Menteri Tenaga Kerja No. 186/MEN/1999 tentang Unit Penanggulangan Bahaya Kebakaran Di Tempat Kerja juga mengatur bahwa setiap perusahaan yang mempekerjakan lebih dari 
50 orang karyawan dan atau tempat kerja yang berpotensi bahaya kebakaran sedang dan berat harus mempunyai sistem proteksi terhadap bahaya kebakaran (Kemnaker RI, 1999). Oleh karena itu perlu dilakukan upaya pencegahan dan penanggulangan terhadap bahaya kebakaran, khususnya pada daerah perindustrian dengan menetapkan sistem proteksi kebakaran yang baik. Menurut PerMen PU No: 26/PRT/M/2008 tentang persyaratan teknis sistem proteksi kebakaran pada bangunan gedung dan lingkungan bahwa sistem proteksi kebakaran pada bangunan gedung dan lingkungan adalah sistem yang terdiri atas peralatan, kelengkapan dan sarana, baik yang terpasang maupun terbangun pada bangunan yang digunakan baik untuk tujuan sistem proteksi aktif, sistem proteksi pasif maupun caracara pengelolaaan dalam rangka melindungi bangunan dan lingkungannya terhadap bahaya kebakaran

Sistem proteksi aktif yang memadai di industri diperlukan untuk keselamatan pekerja. Berdasarkan penelitian yang dilakukan oleh Okta Amalia Putri di PT Reckitt Benckiser Indonesia Semarang disebutkan bahwa keandalan alat-alat pengamanan kebakaran seperti: alarm kebakaran, Titik Panggil Manual (TPM), hidran, alat pemadam sebagai sarana pendukung evakuasi yang mampu memberikan perlindungan secara optimal. Dibandingkan dengan sistem proteksi pasif, sistem proteksi aktif paling awal berperan terhadap pencegahan kebakaran yaitu mencegah timbulnya api kecil; dapat bekerja secara otomatis seperti: alarm, detektor, sprinkler sehingga menunjang keselamatan penghuni saat evakuasi; dan dapat mendeteksi terjadinya api (Ramli, 2010).

Kondisi sistem proteksi kebakaran aktif di PTPN IV Unit PKS Pabatu secara fisik dalam kondisi kurang terpelihara, seperti APAR dan hidran yang sudah berkarat. Berdasarkan uraian tersebut, perlu adanya analisis secara keseluruhan untuk mengetahui kondisi aktual sistem proteksi kebakaran aktif dan tingkat pemenuhan dengan standar acuan. Oleh karena itu, peneliti tertarik untuk melakukan penelitian mengenai analisis penerapan sistem proteksi kebakaran aktif di PTPN IV Unit PKS Pabatu, Serdang Bedagai.

\section{METODE PENELITIAN}

Jenis penelitian yang dilakukan oleh penulis adalah penelitian kualitatif dengan desain studi kasus yang bertujuan untuk menganalisis sistem proteksi kebakaran aktif sebagai upaya pencegahan dan penanggulangan kebakaran di PTPN IV Unit PKS Pabatu. Informan dalam penelitian ini adalah pekerja di PTPN IV PKS Pabatu yang berjumlah 3 orang yaitu PAPAM (Perwira Pengamanan), petugas keamanan dan anggota P2K3. Pemilihan informan karena mereka yang bertanggungjawab mengenai sistem proteksi kebakaran aktif di PTPN IV PKS Pabatu. Penelitian ini dilakukan di PT. Persero Nusantara IV Unit PKS Pabatu, Kecamatan Tebing Tinggi, Kabupaten Serdang Bedagai dimulai pada bulan Juni sampai dengan bulan Agustus 2019.

Penilaian tingkat kesesuaian berdasarkan Standar Nasional, yaitu Permenaker No.Per.02/Men/1983, Kepmen PU No.10/KPTS/2000 dan Permenaker No.Per 04/Men/1980 dengan menggunakan tingkat penilaian audit kebakaran menurut Puslitbang Permukiman Tahun 2005. 
Tabel 1. Tingkat Penilaian Audit Kebakaran

\begin{tabular}{|c|l|l|}
\hline Nilai & \multicolumn{1}{|c|}{ Kesesuaian } & \multicolumn{1}{|c|}{ Keandalan } \\
\hline$>80-100$ & Sesuai persyaratan & Baik (B) \\
\hline $60-80$ & $\begin{array}{l}\text { Terpasang tetapi ada sebagian kecil yang tidak sesuai } \\
\text { persyaratan }\end{array}$ & Cukup (C) \\
\hline$<60$ & Tidak sesuai sama sekali & Kurang (K) \\
\hline
\end{tabular}

Sumber : Puslitbang Permukiman Tahun 2005

Data yang dikumpulkan kemudian diolah dan disajikan dalam bentuk narasi (kalimat), tabel, dan gambar. Hasil tersebut kemudian dibandingkan dengan kesesuaian berdasarkan Permenaker No. Per.02/Men/1983, Kepmen PU No.10/KPTS/2000 dan Permenaker No.Per 04/Men/1980.

\section{HASIL DAN PEMBAHASAN}

Sistem proteksi kebakaran aktif adalah sistem proteksi kebakaran yang secara lengkap terdiri atas sistem pendeteksian kebakaran baik manual ataupun otomatis. Sistem proteksi kebakaran aktif terdiri dari Alarm, APAR, hidran, detektor dan sprinkler. Semua elemen tersebut diidentifikasi dengan observasi menggunakan checklist yang sudah ada.

Tabel 2. Tingkat Kesesuaian Sistem Proteksi Kebakaran Aktif Di PTPN IV KPS Pabatu, Serdang Bedagai Tahun 2019

\begin{tabular}{|c|l|c|}
\hline No & \multicolumn{1}{|c|}{ Elemen } & Persentase \\
\hline 1. & Alarm & $37,5 \%$ \\
\hline 2. & Detektor & $0 \%$ \\
\hline 3. & Hidran & $69,2 \%$ \\
\hline 4. & APAR & $100 \%$ \\
\hline 5. & Sprinkler & $0 \%$ \\
\hline & Tingkat Kesesuaian & $\mathbf{4 1 , 3 4 \%}$ \\
\hline
\end{tabular}

Tingkat kesesuaian alarm kebakaran dibandingkan dengan Permenaker No.Per. 02/MEN/1983. Hasil observasi menunjukkan tingkat kesesuaian sebesar 37,5\% yang artinya tingkat pemenuhan kurang atau tidak sesuai sama sekali. Terdapat alarm kebakaran 1 buah. Alarm berada di ruang kamar mesin dengan tinggi sekitar 1,4 $\mathrm{m}$ dari lantai. Alarm diletakkan di dalam ruang kamar mesin yang menempel pada mesin tombol lain. Jarak alarm lebih dari $30 \mathrm{~m}$ dari semua bagian bangunan dikarenakan letak pabrik yang luas maka alarm berada di bagian tengah. Alarm kebakaran tidak mempunyai gambar instalasi secara lengkap yang mencantumkan letak detektor dan kelompok alarm karena alarm tersebut bukan khusus untuk alarm kebakaran. Alarm tersebut tidak hanya digunakan saat terjadi kebakaran saja tetapi untuk kegunaan lain. Alarm tetap diperiksa dan dipelihara tetapi tidak memiliki prosedur yang tetap. 
Tidak terdapat sistem detektor pada area pabrik PTPN IV Unit PKS Pabatu, baik itu detektor panas, detektor nyala api maupun detektor asap yang berfungsi untuk mendeteksi pada mula kebakaran yang dapat membangkitkan alarm dalam suatu sistem. Hasil observasi menunjukkan tingkat kesesuaian detektor $0 \%$ artinya tidak terpasangnya sistem detektor pada area pabrik PTPN IV Unit PKS Pabatu.

\section{Pembahasan}

Sistem proteksi kebakaran aktif yang ada di PTPN IV Unit PKS Pabatu yaitu alarm kebakaran, hidran dan APAR. Tidak terdapat detektor dan sprinkler. Penerapan sistem proteksi kebakaran aktif dalam upaya pencegahan dan penanggulangan bahaya kebakaran di PTPN IV Unit PKS Pabatu dianalisis dengan membandingkan dengan standar nasional, yaitu Permenaker No.Per.02/Men/1983, Kepmen PU No.10/KPTS/2000 dan Permenaker No.Per 04/Men/1980.

\section{Alarm Kebakaran}

Analisis alarm di Unit PKS Pabatu dibandingkan dengan Permenaker No.Per.02/Men/1983 tentang instalasi alarm kebakaran automatik. Terdapat sistem alarm. Berdasarkan hasil checklist observasi dan wawancara, yaitu di Unit PKS Pabatu terdapat 1 alarm. Alarm manual dengan tipe push button dan jenis sirene yang suara alarm dapat menyeluruh ke semua bagian pabrik. Hal ini sesuai dengan yang dikatakan informan 1, 2 dan 3.

Alarm tidak memiliki bunyi khusus karena alarm tidak hanya digunakan saat terjadi kebakaran saja tetapi juga untuk peringatan-peringatan lainnya. Seperti yang dikatakan oleh informan 1, 2 dan 3. Alarm tidak terhubung dengan sistem sprinkler karena tidak ada sprinkler. Alarm berwarna merah tetapi tidak dapat dilihat dengan jelas karena alarm ditempatkan di atas tangki timbun 1. Alarm diletakkan di dalam ruang kamar mesin yang menempel pada mesin tombol lain. Jarak alarm lebih dari $30 \mathrm{~m}$ dari semua bagian bangunan. Karena jarak alarm dengan bangunan lain cukup jauh maka ada yang telah bertugas untuk membunyikan alarm tersebut. Seperti yang dikatakan oleh informan 1, 2 dan 3.

Menurut hasil penelitian yang dilakukan (Sari, 2016) menyatakan bahwa sistem alarm kebakaran di Hotel Graha Agung Semarang memiliki tingkat pemenuhan kurang baik yang artinya terpasang tapi ada sebagian besar instalasi yang tidak sesuai dengan persyaratan Permenaker No.Per.02/MEN/1983. Padahal menurut Permenaker No.Per.02/MEN/1983 bahwa sistem alarm merupakan salah satu dari sistem proteksi kebakaran aktif yang dapat mencegah dan menanggulangi saat terjadinya kebakaran.

Rekomendasinya yaitu alarm diletakkan pada lintasan jalur keluar dengan tinggi tidak lebih dari 1,4 m dari lantai agar alarm mudah untuk di periksa jika terjadi kerusakan. Memiliki alarm khusus kebakaran atau alarm kebakaran automatik yang menggunakan detektor panas. Alarm juga harus mempunyai gambar instalasi secara lengkap yang mencantumkan letak detektor dan kelompok alarm. Alarm harus mempunyai prosedur pemeliharaan.

\section{Detektor}

PTPN IV Unit PKS Pabatu tidak memiliki detektor, karena menurut ketiga informan bahwa detektor tidak dibutuhkan di pabrik tersebut. Informan juga menjelaskan jika terjadi kebakaran apa saja 
yang akan dilakukan dari awal terjadinya kebakaran sampai dengan pelaporan. Pertama, bunyikan alarm agar seluruh pekerja dapat melakukan langkah pengamanan seperti mengevakuasi dokumendokumen penting dan menuju titik evakuasi. Kedua, padamkan api dengan APAR. Ketiga, jika api tidak padam dan kebakaran semakin membesar maka hubungi tim pemadam kebakaran. Terakhir, jika ada kerugian dan korban jiwa akan membuat pelaporan. Seperti yang dijelaskan informan 1, 2 dan 3. Menurut ketiga informan PTPN IV Unit PKS Pabatu juga memiliki manajemen kebakaran seperti kebijakan manajemen, organisasi prosedur, pelatihan, tim pemadam kebakaran dan pelaporan.

Detektor sangat penting untuk mendeteksi adanya panas, jika terjadi kebakaran detektor dapat mendeteksi adanya api lewat bunyi alarm sehingga kebakaran cepat di atasi. Menurut hasil penelitian yang dilakukan (Kurniawan, 2014) menyatakan bahwa sistem detektor memiliki tingkat pemenuhan cukup baik yang artinya terpasang tapi ada sebagian kecil instalasi yang tidak sesuai dengan persyaratan Permenaker No.Per.02/MEN/1983.

Rekomendasi yang dapat diberikan adalah pihak pabrik melengkapi sistem proteksi kebakaran berupa detektor sesuai dengan Permenaker No. Per.02/Men/1983. Seharusnya terdapat sistem pendeteksi dini bahaya kebakaran, detektor harus dipasang pada bagian bangunan kecuali apabila bagian bangunan tersebut telah dilindungi dengan sistem pemadam kebakaran automatik. Detektor yang cocok digunakan di area pabrik yaitu detektor panas. Detektor panas adalah peralatan dari detektor kebakaran yang dilengkapi dengan suatu rangkaian listrik atau pneumatik yang secara otomatis akan mendeteksi kebakaran melalui panas yang diterimanya. Sistem detektor panas juga beragam seperti detektor suhu tetap, detektor suhu berubah, detektor peningkatan suhu. Jarak detektor panas dengan tembok atau dinding pembatas paling jauh $3 \mathrm{~m}$ pada ruang biasa dan $6 \mathrm{~m}$ dalam koridor serta paling dekat $30 \mathrm{~cm}$. Elemen sensor pada detektor dalam keadaan bersih dan tidak dicat. Untuk setiap $46 \mathrm{~m}^{2}$ luas lantai dengan tinggi langit-langit dalam keadaan rata tidak lebih dari $3 \mathrm{~m}$ harus dipasang sekurang-kurangnya satu buah detektor panas.

\section{Hidran}

Analisis hidran di Unit PKS Pabatu dibandingkan dengan Keputusan Menteri Negara Pekerjaan Umum No: 10/KPTS/2000 tentang ketentuan teknis pengamanan terhadap bahaya kebakaran pada bangunan gedung dan lingkungan. Di Unit PKS Pabatu terdapat 4 hidran halaman. Semua kotak hidran di kunci untuk mengantisipasi agar nozzle tidak hilang. Kunci kotak hidran tersebut di simpan di pos piket keamanan, jika terjadi kebakaran maka petugas keamanan lah yang membuka kotak hidran. Hal ini sesuai dengan yang dikatakan oleh informan 1, 2 dan 3.

Sebagian kotak hidran berwarna merah dan sebagian lagi berwarna coklat karena tidak terawat. Sebaiknya kotak hidran lebih diperhatikan agar mudah untuk pengoperasian hidran.

Sistem hidran terdiri dari pemipaan, katup, sambungan selang, dan kesatuan peralatan dalam bangunan, dengan sambungan selang dipasangkan sedemikian rupa sehingga air dapat dikeluarkan dalam aliran atau pola semprotan melalui selang dan pipa pemancar yang dihubungkan untuk keperluan memadamkan api. Ini dapat dicapai dengan menghubungkannya ke pasokan air atau dengan menggunakan pompa untuk menyediakan masukan air yang cukup ke sambungan selang. Sumber air hidran berasal dari bengkel air yang di dapat dari sungai. Seperti yang dikatakan oleh informan 1, 2 dan 3 
Sebagian peralatan hidran dicat merah dan kotak hidran berwarna merah bertuliskan "HIDRAN" yang dicat putih, sebagian lagi bewarna coklat yang terbuat dari kayu karena tidak terawat. Diameter selang 2 inci dan menggunakan pipa tegak 6 inci. Terdapat petunjuk penggunaan yang dipasang ditempat yang mudah dilihat. Semua hidran tidak memiliki petunjuk penggunaan yang tercantum pada kotak hidran atau menempel di dinding. Terdapat kelengkapan hidran seperti selang, sambungan selang, nozzle, dan kran pembuka. Hanya 1 hidran yang memiliki kelengkapan tersebut. Pada kotak hidran halaman di ruang timbangan tidak terdapat nozzle, dan kotak hidran lainnya isinya kosong.

Hidran dalam keadaan siap digunakan. Terdapat 3 hidran yang peralatannya tidak lengkap dan hidran halaman isinya kosong, hal itulah yang membuat hidran-hidran tersebut tidak siap untuk digunakan. Alasan informan karena mengantisipasi agar tidak hilang, berhubung selang dan nozzle yang ada di pabrik sering hilang. Selang dan nozzle ada tetapi di simpan di dalam gudang, jika ada kejadian kebakaran maka selang dan nozzle akan dipasang. Dilakukan pemeriksaan hidran setiap 6 bulan sekali. Hidran selalu diperiksa oleh anggota P2K3 setiap 6 bulan sekali.

Menurut hasil penelitian yang dilakukan (Amrullah, 2010) menyatakan bahwa sistem hidran di Area Pabrik PT. Sentrafood Indonusa memiliki tingkat pemenuhan baik yang artinya terpasang tapi ada sebagian kecil instalasi yang tidak sesuai dengan persyaratan Keputusan Menteri Negara Pekerjaan Umum No: 10/KPTS/2000.

Rekomendasi yang dapat diberikan adalah pabrik melengkapi petunjuk penggunaan hidran agar hidran dapat digunakan untuk memadamkan api. Dengan adanya petunjuk penggunaan maka hidran dapat dioperasikan dengan benar. Isi dari petunjuk penggunaan hidran seperti buka pintu box hidran, keluarkan/tarik slang dan nozzle, uraikan selang dan buka kran hidran kearah kiri. Pabrik juga melengkapi kelengkapan peralatan hidran agar hidran dapat digunakan untuk melakukan pemadaman kebakaran pada tahap awal dan sebelum membesar. Memperbaiki kotak hidran yang rusak dan melengkapi kotak hidran yang kosong. Karena bencana dapat terjadi secara tiba-tiba dan tidak dapat diprediksi sehingga kapan pun terjadi kebakaran yang tidak dapat ditanggulangi oleh alat proteksi kebakaran lainnya, dapat langsung menggunakan hidran. Anggota P2K3 melakukan pemeriksaan secara menyeluruh pada setiap komponen-komponen yang mendukung fungsi hidran tersebut. Dalam pemeriksaan hidran yang dilakukan seperti kondisi dan kelengkapan kotak hidran, sambungan hidran dan pemipaan, selang dan pompa.

\section{Sprinkler}

PTPN IV unit PKS Pabatu tidak memiliki sprinkler. Seperti yang dikatakan oleh informan 1, 2 dan 3. Menurut hasil penelitian Sari, 2016 yang menyatakan bahwa Hotel Graha Agung Semarang juga tidak memiliki sprinkler yang artinya perusahaan lain juga belum menyadari betapa pentingnya sistem sprinkler, padahal sprinkler merupakan salah satu upaya pencegahan dan penanggulangan kebakaran.

Rekomendasi yang dapat diberikan adalah pihak pabrik melengkapi sistem proteksi kebakaran berupa sprinkler sesuai dengan Kepmen PU No.10/KPTS/2000. Sprinkler dipasang secara tetap/permanen di dalam bangunan sehingga dapat memadamkan kebakaran secara otomatis dengan menyemprotkan air di tempat terjadinya kebakaran. Sistem sprinkler ini sebaiknya dipasang disekitar 
area yang memiliki resiko kebakaran tinggi, seperti diruangan proses produksi dan ruang gudang penyimpan. Setiap sistem sprinkler otomatis harus dilengkapi dengan sekurang-kurangnya satu jenis sistem penyediaan air yang bekerja secara otomatis, bertekanan dan berkapasitas cukup, serta dapat diandalkan setiap saat. Air yang digunakan tidak boleh mengandung serat atau bahan lain yang dapat mengganggu bekerjanya sprinkler. Jarak maksimum antara kepala sprinkler dalam satu deretan adalah 4,6 m, jarak minimum antara dua kepala sprinkler tidak boleh kurang dari $2 \mathrm{~m}$.

\section{APAR}

Tingkat pemenuhan APAR di PTPN IV Unit PKS Pabatu yaitu 100\% sesuai dengan Permenaker No.Per 04/Men/1980 tentang syarat-syarat pemasangan dan pemeliharaan alat pemadam api ringan. Di Unit PKS Pabatu mempunyai 25 APAR yang tersebar diseluruh area pabrik. Untuk 23 APAR berwarna merah dan 2 berwarna biru. APAR diletakkan menggantung di dinding dengan penguat sengkang besi yang tidak dikunci dan tidak terhalang benda lain sehingga mudah diambil. Tinggi APAR dari lantai 1,4 m sehingga mudah untuk dicapai. Unit PKS Pabatu menggunakan 3 jenis APAR roda dan 22 jenis APAR menggantung. APAR dalam kondisi baik dan siap pakai. APAR digunakan ketika tahap penyulutan yaitu api kecil, keadaan ini akan membuat seseorang harus berindak dengan cepat sehingga menggunakan APAR yang terdekat. Seperti yang dikatakan oleh ketiga informan bahwa semua pekerja mengetahui dimana ditempatkannya APAR, hidran dan alarm tetapi pekerja hanya mengetahui cara penggunaan APAR dan alarm.

Informan 1, 2 dan 3 juga mengatakan bahwa PAPAM, petugas keamanan dan anggota P2K3 melakukan pelatihan terkait pencegahan dan penanggulangan kebakaran setiap satu tahun sekali. APAR diperiksa setiap 3 bulan sekali. Berdasarkan hasil checklist observasi dan wawancara semua APAR di Unit PKS pabatu diperiksa setiap 3 bulan, hal ini dibuktikan dengan adanya kartu catatan menempel pada APAR yang mencantumkan tanggal berlaku dan tanggal pemeriksaan.

Petunjuk cara pemakaian APAR harus dapat dibaca dengan jelas. Berdasarkan hasil checklist observasi dan wawancara semua APAR tercantum cara penggunaan APAR yang dapat dibaca dengan jelas. Petunjuk cara pemakaian APAR tersebut terdapat pada label APAR yang tertempel pada tabung APAR. Hal ini berguna bagi seseorang yang akan menggunakan APAR tetapi tidak mengetahui cara menggunakannya dan tidak pernah mengikuti pelatihan sehingga APAR dapat digunakan secara optimal. Petunjuk cara penggunaan APAR yaitu tarik/lepas pin pengunci tuas APAR, arahkan selang ke titik pusat api, tekan tuas untuk mengeluarkan isi APAR,sapukan secara merata sampai api padam. Hal yang perlu diketahui dalam penggunaan APAR yaitu memerhatikan arah angin dengan badan menghadap searah dengan arah angin efektif menuju ke pusat api dan jilatan api tidak mengenai tubuh, memerhatikan jenis kebakaran yang terjadi dengan menyesuaikan penggunaan APAR.

Penempatan APAR yang satu dengan lainnya tidak boleh lebih dari $15 \mathrm{~m}$, kecuali ditetapkan oleh ahli keselamatan kerja atau pegawai pengawas. Semua APAR berjenis serbuk kimia kering atau tepung. Setiap APAR harus dipasang menggantung pada dinding dengan penguatan sengkang atau ditempatkan dalam lemari atau peti (box) yang tidak dikunci. Dipasang menggantung agar APAR mudah diambil dan dilihat.

Warna dasar tanda pemasangan APAR yaitu merah. Berdasarkan hasil checklist observasi dan wawancara, semua APAR memiliki segel pengaman dan penutup tabung yang tidak rusak. Lubang 
penyemprot tidak tersumbat dan selang tahan tekanan tinggi serta tidak bocor. Lubang pada penyemprot tidak terdapat sumbatan karena benda lain dan kondisi selang tidak rusak. Apabila segel telah terlepas atau putus dikhawatirkan APAR telah digunakan.

APAR dalam kondisi baik dan diperiksa secara berkala. Semua APAR dalam kondisi baik, hal itu dapat terlihat pada kartu catatan yang tertempel pada APAR. Rekomendasi yang dapat diberikan adalah pemeriksaan pada fisik tabung yaitu tidak adanya karat atau keropos pada bagian dasar dan leher tabung. Apabila terdapat karat dan cacat maka harus segera dibersihkan atau diganti dengan yang baru. Pemeriksaan pada selang yaitu biasanya bagian dalam selang terdapat sumbatan atau tidak, kebocoran pada selang. Selang yang bocor atau patah hendaknya segera diganti karena selang yang rusak akan membahayakan bagi pemakai APAR akibat zat kimia dapat mengenai mata atau terhirup.

Isi tabung gas sesuai dengan tekanan yang dipergunakan dan dijaga tetap penuh. Tekanan pada semua APAR memiliki tekanan penuh yaitu jarum menunjukkan pada warna hijau. Pada APAR terdapat pressure gauge yang menyatakan tekanan pada tabung, tekanan yang benar yaitu jarum pada manometer masih pada zona hijau. Menurut hasil penelitian yang dilakukan (Kurniawan, 2014) menyatakan bahwa tingkat pemenuhan APAR baik yang artinya terpasang tapi ada sebagian kecil instalasi yang tidak sesuai dengan persyaratan Permenaker No.Per 04/Men/1980. Rekomendasinya yaitu perlu adanya peninjauan ulang dari pihak PTPN IV terhadap keadaan APAR, agar dapat memudahkan saat digunakan.

\section{Keterbatasan Penelitian}

Keterbatasan peneliti dalam melakukan penelitian ini adalah :

1. Tidak semua sistem proteksi kebakaran dapat dilakukan pengukuran sendiri oleh peneliti seperti dalam pengukuran debit air pada hidran dan pengecekan APAR dikarenakan tidak diberi izin.

2. Tidak dapat melakukan pemeriksaan alarm kebakaran dikarenakan proses produksi sedang berlangsung.

\section{Kesimpulan}

Berdasarkan penelitian yang telah dilakukan dapat disimpulkan bahwa penerapan sistem proteksi kebakaran sebagai upaya pencegahan dan penanggulangan kebakaran di Unit PKS Pabatu yaitu :

1. Hanya 37,5\% sistem alarm yang sesuai dengan Permenaker No.Per.02/MEN/1983.

2. Tidak terdapat detektor

3. Sebesar 69,2\% sistem hidran sesuai dengan Keputusan Menteri PU No.10/KPTS/2000.

4. Tidak terdapat sprinkler

5. Alat Pemadam Api Ringan (APAR) menunjukkan bahwa 100\% sesuai dengan Permenaker No.04/Men/1980.

\section{Saran}

Dari penelitian yang telah dilakukan, ada beberapa saran yang direkomendasikan, antara lain : 
1. Pihak PTPN IV perlu melakukan peninjauan ulang letak alarm yang terdapat di pabrik.

2. Pengadaan sistem detektor untuk mendeteksi dengan cepat apabila terjadi keadaan darurat kebakaran.

3. Sebaiknya PTPN IV melengkapi peralatan pada box hydrant halaman yaitu selang dan nozzle agar pada saat terjadi kebakaran hidran berfungsi secara optimal, memperbaiki box hydrant yang sudah rusak dan memasang petunjuk penggunaan hidran yang ditempel pada box hydrant atau dinding sehingga semua karyawan pabrik mengetahui cara penggunaan hidran sesuai dengan Kepmen PU No.10/KPTS/2000.

4. Perlu adanya peninjauan ulang dari pihak PTPN IV terhadap kondisi APAR yang kotor supaya mudah digunakan .

5. Sebaiknya PTPN IV menambahkan sistem sprinkler yaitu terdapat jaringan dan persediaan air bersih yang bebas lumpur serta pasir, jarak antar sprinkler tidak lebih dari 4,6 m, terhubung otomatis dengan alarm kebakran, kepala sprinkler dalam keadaan baik tidak terhalang benda lain, melakukan pemeriksaan dan uji coba minimal 1 tahun sekali.

\section{DAFTAR PUSTAKA}

Amrullah, F. I. (2010). Analisis Tingkat Pemenuhan Sarana Proteksi Aktif Dan Sarana Penyelamatan Jiwa Di Area Pabrik PT.Sentrafood Indonusa Tahun 2010.

Anizar (2010) Tehnik Keselamatan dan Kesehatan Kerja di Industri. pertama. yogyakarta: graha ilmu.

Arikunto, S. (2013) Prosedur Penelitian Suatu Pendekatan Praktik. Jakarta: PT. Rineka Cipta.

Ashari, M. L. et al. (2018) Sosialisasi Kebakaran Dan Penangannya Pada Siswa Sekolah Dasar Di Surabaya Guna Meningkatkan Self-Readiness Terhadap Bencana Kebakaran, pp. 2124.

Azmi, U. and S.L, F. (2018) Sistem Proteksi Kebakaran Aktif di Badan Rumah Sakit Daerah Luwuk Kabupaten Banggai, Kesmas Untika Luwuk, 9.

Bachri, B. S. (1986) Meyakinkan Validitas Data Melalui Triangulasi pada Penelitian Kualitatif'.

Kemnaker, RI. (1999) Keputusan Menteri Tenaga Kerja No. 186/MEN/1999 tentang Unit Penanggulangan Kebakaran di Tempat Kerja.

Keputusan Menteri Pekerjaan Umum No. 26/PRT/M/2008 tentang Persyaratan Teknis Sistem Proteksi Kebakaran Pada Bangunan Gedung Dan Lingkungan.

Keputusan Menteri Pekerjaan Umum Nomor 10 Tahun 2000 Ketentuan Teknis Pengamanan Terhadap Bahaya Kebakaran pada Bangunan Gedung dan Lingkungan.

Keputusan Menteri Tenaga Kerja No. 189/MEN/1999 tentang Unit Penanggulangan Kebakaran di Tempat Kerja.

Kowara, R. A. and Martiana, T. (2017) Analisis Sistem Proteksi Kebakaran Sebagai Upaya Pencegahan dan Penanggulangan Kebakaran (Studi di PT. PJB UP Brantas Malang), Manajemen Kesehatan, 3(1), pp. 70-85.

Kurniawan, A. (2014). Gambaran Manajemen Dan Sistem Proteksi Kebakaran Di Gedung Fakultas Kedokteran Dan Ilmu Kesehatan Univesitas Islam Negeri Jakarta Tahun 2014.

Peraturan Menteri Tenaga Kerja Dan Transmigrasi No Per.04/Men/1980 Tentang Syarat-Syarat Pemasangan Dan Pemeliharaan Alat Pemadam Api Ringan.

Priambudi, B. S., Kurnawan, B. and Widjasena, B. (2017) Telaah Kesiapsiagaan Manajemen Terhadap Kondisi Darurat Kebakaran di PT. X (Pulp \& Paper) Tahun 2017, Kesehatan Masyarakat, 5, pp. 336-345.

Ramli, S. (2010) Pedoman Praktis Manajemen Bencana (Disaster Management). Dian Rakya. Edited by Husjain Djajaningrat.

Sari, C. P. (2016). Evaluasi Penerapan Sarana Proteksi Aktif Pencegahan Kebakaran Di Hotel Graha Agung Semarang Tahun 2015.

Sugiyono (2008) Metode Penelitian Kuantitatif Kualitatif dan R\&D. Edited by Alfabeta. Bandung. Suprapto, 2007, Sistem Proteksi Kebakaran Pasif Kaitannya Dengan Aspek Keselamatan Jiwa (Passive Fire Protection And Life Safety), jurnal Pusat Litbang Permukiman.

Syahri, E. A. (2011) Upaya Pencegahan dan Penanggulangan Bahaya Kebakaran di PT . Pura 
Journal of Healthcare Technology and Medicine Vol. 6 No. 2 Oktober 2020 Universitas Ubudiyah Indonesia

e-ISSN : 2615-109X

Barutama.

Tarwaka (2012) Dasar-dasar Keselamatan Kerja serta Pencegahan Kecelakaan di Tempat kerja. Surakarta: Harapan Press.

Undang-undang Republik Indonesia Nomor 1 tahun 1970 tentang Keselamatan Kerja. 